\title{
Süt Sığırlarında Gebelik Oranı Üzerine Etkili Bazı Faktörlerin Lojistik Regresyon Analizi ile Değerlendirilmesi
}

\author{
Aytaç Akçay $^{1 *}$, Murat Abay ${ }^{2}$, Tayfur Bekyürek \\ ${ }^{1}$ Erciyes Üniversitesi, Veteriner Fakültesi, Biyometri Anabilim Dalı, Kayseri, Türkiye \\ ${ }^{2}$ Erciyes Üniversitesi, Veteriner Fakültesi, Doğum ve Jinekoloji Anabilim Dalı, Kayseri, Türkiye \\ *e-posta: aakcay@erciyes.edu.tr; Tel:+90 (352) 207 6666/ 29735; Faks: +90 (352) 3372740
}

\begin{abstract}
Özet
Bu çalışmada, süt sığırcıllı̆̆ ekonomisinde önemli yer tutan ineklerde tohumlama sonrasında 30. günde yapılan muayenede, gebelik oranı üzerine etkili bazı faktörlerinin etki paylarının hesaplanması amaçlanmıştır. Çalışmanın materyalini, Plato Entegre Hayvancılık ve Tarım San. Tic. A.Ş’de yetiştirilen 126 baş Holştayn ineğe ait verim ve performans kayıtları oluşturmuştur. İneklere ait; senkronizasyon yöntemi, doğum sayısı, tohumlama günündeki süt verimi, vücut kondisyon skoru, postpartum süre ve tohumlama sayısı değişkenlerinin tohumlama sonrasında 30. günde belirlenen gebelik oranı ile ilişkilerinin belirlenmesi lojistik regresyon analizi ile yapılmıştır. Çok değişkenli lojistik regresyon modelinde geriye doğru değişken çıkarma yöntemi uygulanmıştır. Oluşturulan lojistik model katsayılarının tahmininde en çok olabilirlik yöntemi kullanılmıştır. Çalışma kapsamına alınan ineklerde tohumlama sonrasında 30. günde transrektal ultrasonografi yöntemi ile yapılan gebelik muayenesinde $\% 45.2$ gebelik saptanmıştır. Çok değişkenli lojistik regresyon analizinde kullanılan geriye doğru değişken çıkarma yöntemi 3. adımda sonlanmıştır. Modelin ineklerde gebelik oranını açıklamadaki etkinliği Hosmer-Lemeshow uyum iyiliği istatistiği önem değeri 0.891 olarak hesaplanmıştır. Final model ile kestirilen olasılıklar kullanılarak, modelin gebeliği doğru tanı oranı \% 65 olarak belirlenmiştir. Çalışma sonucunda, elde edilen final modelde yer alan; "senkronizasyon yöntemi, tohumlama anındaki süt verimi, vücut kondisyon skoru, tohumlama sayısı” değişkenlerinin gebelik oranı üzerine etkili faktörler olduğu belirlenmiştir.
\end{abstract}

Anahtar kelimeler: Gebelik oranı, lojistik regresyon, odds oranı, süt sığırı

\section{Evaluation of Some Factors Effective on Conception Rates Using Logistic Regression Analysis in Dairy Cattle}

\begin{abstract}
The aim of this study was calculate the effects of some factors that is have importance in the economy of dairy cattle $30^{\text {th }}$ day conception rates after the insemination. Materials of this study consisted efficiency and performance records of 126 Holstein cows grown in "Plato Entegre Hayvancılık ve Tarım San. Tic. A.Ş". Logistic regression analysis was used to determination of conception rates in relation with variable which is synchronization method, parity, seeding at the time of milk yield, body condition score, post-partum period and number of artificial insemination. In the multivariable model, variables were excluded from the model by the backward elimination procedure. Maximum likelihood method is used for estimating the coefficients in the logistic regression model. In this study; 30th day after insemination in cows by the method of transrectal ultrasonography in the inspection the conception has been identified in $45.2 \%$ of conception rate. In the multivariable logistic regression model was completed in 3rd step by using the backward elimination procedure. The model's effectiveness on conception rate in cows, Hosmer-Lemeshow goodness of fit statistics significance value was calculated as 0.891 . Model's overall classification ratio was determinated as \% 65 using final model's estimated probabilities. As a result, in the final model "synchronization method, seeding at the time of milk yield, body condition score and number of artificial insemination" has been determined that the effective factors of 30th day conception rate.
\end{abstract}

Key words: Conception rates, dairy cattle, logistic regression, odds ratio

\section{Giriş}

Süt sığırı yetiştiriciliğinde verimliliği belirleyen en önemli özelliklerden birisi düzenli döl verimidir ve bu da ineklerin doğumdan sonra ideal sınırlar içinde gebe kalmalarını sağlayarak, yılda bir yavru elde etmekle mümkün olabilmektedir. $\mathrm{Bu}$ amaçla süt sı̆̆ırı yetiştiriciliğinde, döl verimi üzerine etkili mevsim, buzağılama yaşı ve laktasyon sayısı gibi çevre faktörlerinin araştırıldığı (Özçakır ve Bakır, 2003; Galiç ve ark., 2004; Sehar ve Özbeyaz, 2005; Türkyılmaz, 2005; Erdem ve ark., 2007); süt- döl verimi ilişkilerinin incelendiği (Duru ve Tuncel, 2004; Uğur ve ark. , 2006 Kaya ve ark. 2003); ekonomik değerlendirmelerin yapıldığ1 (Kumuk ve ark., 1999; Pirlo et al., 2000; Kaygisız ve ark., 2008), genetik parametrelerin tahmine 
yönelik (Ertuğrul ve ark., 2002; Koç ve ark., 2004; Ulutaş ve ark., 2004) ve senkronizasyon yöntemlerinin karşılaştırıldığı (Pursley et al., 1997; Zonturlu ve ark., 2004; Sabo et al., 2008) çalışmalara sıklıkla yer verilmiştir.

Lojistik regresyon analizi, bağımlı (sonuç) değişkenin ikili veya sıralı olması durumunda, bağımlı değişken ile bağımsız değişkenler arasındaki neden sonuç ilişkisini belirlemede kullanılan bir yöntemdir (Özdamar, 2002). Veteriner hekimlik alanında lojistik regresyon analizi ile yapılan araştırmalar daha çok belli bir hastalığın oluşumunda etkili olan risk faktörlerinin belirlenmesi amacını taşımaktadır. $\mathrm{Bu}$ araştırmalarda öncelikle hastalıkla ilgili bağımsız değişkenler tanımlanmış ve bu değişkenler ile araştırma konusunu oluşturan verim özellikleri veya hastalıklara ait sonuçlar arasındaki ilişkiler araştırılmıştır (Cameron et al. 1998; Bartels et al. 1999; Opsomer et al.,2000; Gröhn and RajalaSchultz, 2000; Bruun et al., 2002; López-Gatius et al.,2002).

Günümüzde sığır yetiştiriciliğinde, gebelik başına tohumlama sayısının yüksek olması, ideal olmayan vücut kondisyonu skoru, postpartum sürenin uzunluğu önemli problemlerin arasında başta gelmektedir. Süt sığırlarında gebelik oranı üzerine etkili faktörlerinin belirlenmesi, verimlilik ve ekonomik kayılarının azaltılması açısından önemlidir. Bu çalışmada, ineklerde tohumlama sonrasında 30 . günde yapılan muayenede tespit edilen gebelik oranı üzerine etkili bazı faktörlerinin etki paylarının lojistik regresyon analizi ile hesaplanması ve her bir işlem adımının sırasıyla nasıl değerlendirileceğine iliş̧kin bilgiler sunulmuştur.

\section{Materyal ve Metot}

Çalışmanın materyalini, Kayseri ili Bünyan ilçesinde yer alan Plato Entegre Hayvancılık ve Tarım San. Tic. A.Ş'de yetiştirilen 126 baş Holştayn ineğe ait döl verimi ve performans kayıtları oluşturmuştur. Süt sığırlarında gebelik oranı üzerinde etkili olduğu düşünülen bazı faktörlerin etki paylarının belirlenmesi amacına yönelik lojistik regresyon analizi kullanılarak yapılan bu çalışmada uygulamaya dahil edilen 126 inek, tohumlama sonrası 30 . günde transrektal ultrasonografi yöntemi ile belirlenen gebelik muayenesi sonuçlarına göre gebelik var (1) ya da yok (0) olarak nitelendirilmiştir. Gebelik durumu iki sonuçlu değer alabilen kategorik (kesikli, sınıflı) bağımlı değişken (Y) olarak tanımlanmıştır. Çalışmada lojistik modele girmeye aday değişkenler olarak belirlenen senkronizasyon yöntemi kategorik bağımsız değişken (doğal östrus gösterenler (1), progesteron preparatı ile östrusu senkronize edilenler (2)); doğum sayısı, süt verimi (tohumlama günündeki), vücut kondisyon skoru (tohumlama günündeki), postpartum süre ve tohumlama say1s1 (son postpartum dönemde ineklere yapilan tohumlama sayısı) ise sürekli bağımsız değişkenler olarak alınmıştır.

İlk olarak tüm değişkenler üzerine tek değişkenli lojistik regresyon analizi uygulanarak değişkenlerin gebelik oranı üzerindeki etkileri belirlenmiştir. İkinci olarak; lojistik regresyon analizinde adımsal (Stepwise) yöntemlerden, ileriye doğru (forward) yönteminin baskılama etkisi (supressor) göz önüne alınarak, geriye doğru değişken çıkarma yöntemi tercih edilmiştir (Çokluk, 2010). Çok değişkenli modeldeki değişkenlerin model içindeki önemliliği Wald testi ile belirlenmiş̧ir. Wald istatistiği, lojistik regresyonda $\beta$ katsayısının anlamlılık testine karşılık gelir. Wald istatistiği en çok olabilirlik kestirimlerinin (maximum likelihood estimations) asimptotik olarak normal dağılım gösterdiği varsayımına dayanır ve 1 serbestlik dereceli ki-kare dağılımı gösterir. Çalışmada, Wald istatistiği tarafindan belirlenen etkilerinin anlamlı olup olmamasına göre değişkenler modelden çıkarılmıştır (Çokluk, 2010). Modelin gebelik oranını açıklamadaki etkinliği Deviance (Sapma) ve ki- kare uyum iyiliği ölçütleri ile hesaplanmıştır. Oluşturulan lojistik model katsayılarının tahmininde en çok olabilirlik yöntemi kullanılmıştır. Final modelin uyum iyiliği testi HosmerLemeshow ( $\hat{C}_{g}^{*}$ ) istatistiği ile test edilmiş ve modelden elde edilen kestirilen olasılıklar kullanılarak, modelin gebelik görülen ve görülmeyen inekler arasındaki ayrımsama gücü belirlenmiştir. Final modelin yorumlanması odds oranları $(\mathrm{OR}, \operatorname{Exp}(\beta))$ kullanılarak yapılmıştır. Odds oranı, bağımlı değişkenin bağımsız değişkenin etkisi ile kaç kat daha fazla (\% kaç oranında daha fazla) gözlenme olasılığına sahip olduğunu belirtir. Temel istatistik yöntemler ve lojistik regresyon analizi SPSS for Windows 14.01 (Lisans No: 9869264) paket programı kullanılarak yapılmışıır

\section{Bulgular}

İneklerde tohumlama sonrasinda 30 . günde yapilan erken gebelik teşhisi, süt sığırcıllı̆ı ekonomisinde önemli yer tutar. $\mathrm{Bu}$ çalışma kapsamındaki tüm ineklerde tohumlama sonrasinda 30. günde yapilan muayenede gebelik oran1 \% 45.2 (57/126) olarak saptanmıştır. $\mathrm{Bu}$ oran östrus senkronizasyonu yapılanlarda \% 51.3 (39/76), doğal östrus gösterenlerde $\% 36(18 / 50)$ bulunmuştur. 
Çizelge 1. Gebelik durumuna göre incelenen değişkenlere ait tanımlayıcı istatistikler

\begin{tabular}{lcccc}
\hline Değişkenler & \multicolumn{2}{c}{ Gebelik $(-)$} & $\mathrm{N}$ & $\bar{X} \pm S$ \\
\hline Doğum sayıs1 & $\mathrm{N}$ & $\bar{X} \pm S$ & 57 & $1.95 \pm 0.23$ \\
Süt Verimi & 69 & $1.90 \pm 0.30$ & 57 & $25.59 \pm 8.22$ \\
Vücut Kondisyon skoru & 67 & $28.75 \pm 7.62$ & 56 & $2.71 \pm 0.39$ \\
Postpartum süre & 69 & $2.62 \pm 0.31$ & 57 & $176.77 \pm 109.91$ \\
Tohumlama sayıs1 & 69 & $170.71 \pm 145.19$ & 57 & $2.19 \pm 1.78$ \\
\hline
\end{tabular}

Gebelik muayenesi sonuçlarına göre sinıflandırılan (gebelik var/yok) 126 baş Holştayn ineğe ait tanımlayıcı istatistikler Çizelge 1'de verilmiştir.

İncelenen değişkenlerin önce tek değişkenli lojistik regresyon analizi yapılarak gebelik ile ilişkileri incelenmiştir. Değişkenlere ait modelleri içeren çizelgede,

$\hat{\beta}:$ Kestirilen eğim katsayısı; $S E(\hat{\beta})$ : Kestirilen eğim katsayısının standart hatası; Wald : Model için eğim katsayılarının sıfıra eşit olup olmadığını test eden Wald istatistiği; P: Wald istatistiğine ait $\mathrm{P}$ değeri; $\mathrm{OR}$ : Kestirilen odds oranı ve buna ait $\% 95$ güven aralığ verilmiş̧ir (Çizelge 2).

Çok değişkenli lojistik regresyon modeline girecek değişkenlerin her biri için ayrı ayrı yapılan tek değişkenli lojistik regresyon analiz sonuçları Çizelge 2'de özetlenmiştir. Belirlenen değişkenler çok değişkenli lojistik modelde kullanılmıştır. Geriye doğru değişken çıkarma yöntemi ile ilk aşamada tüm değişkenler modele dahil edilmiş, kriterlere uymayan değişkenlerin modelden çıkarılması 3 adımda tamamlanmıştır. Her adım sonunda modelde kalan ve modelden çıkarılan değişkenler Çizelge 3'de verilmiştir.

Çizelge 2. Tek değişkenli lojistik regresyon modelleri

\begin{tabular}{|c|c|c|c|c|c|c|c|c|}
\hline Değişken & Değişken Sınırları & $\widehat{\boldsymbol{\beta}}$ & $\mathbf{S E}(\widehat{\boldsymbol{\beta}})$ & Wald & $\begin{array}{c}\mathrm{P} \\
\text { Değeri }\end{array}$ & OR & \multicolumn{2}{|c|}{$\begin{array}{l}\text { OR'nin \%95 } \\
\text { Güven Aralığ1 }\end{array}$} \\
\hline \multirow{3}{*}{ Senkronizasyon Yöntemi } & Doğal (Referans) & 0.00 & 0.00 & & & 1.000 & 1.000 & 1.000 \\
\hline & Senkronizasyon & 0.628 & 0.373 & 2.828 & 0.093 & 1.874 & 0.901 & 3.896 \\
\hline & Sabit & -0.575 & 0.295 & 3.814 & 0.051 & 0.563 & & \\
\hline \multirow{2}{*}{ Doğum say1s1 } & Doğum sayıs1 & 0.709 & 0.715 & 0.984 & 0.321 & 2.032 & 0.501 & 8.248 \\
\hline & Sabit & -1.556 & 1.393 & 1.249 & 0.264 & 0.211 & & \\
\hline \multirow{2}{*}{ Süt Verimi } & Süt Verimi & -0.053 & 0.024 & 4.680 & 0.031 & 0.948 & 0.904 & 0.995 \\
\hline & Sabit & 1.291 & 0.695 & 3.453 & 0.063 & 3.638 & & \\
\hline \multirow{2}{*}{ Vücut kondisyon skoru } & VKS & 1.066 & 0.531 & 4.021 & 0.045 & 2.903 & 1.024 & 8.227 \\
\hline & Sabit & -2.964 & 1.388 & 4.558 & 0.033 & 0.052 & & \\
\hline \multirow{2}{*}{ Postpartum süre } & PPS & $<0.001$ & 0.001 & 0.068 & 0.794 & 1.000 & 0.998 & 1.003 \\
\hline & Sabit & -0.254 & 0.299 & 0.719 & 0.397 & 0.776 & & \\
\hline \multirow{2}{*}{ Tohumlama sayıs1 } & $\mathrm{TS}$ & -0.025 & 0.085 & 0.085 & 0.770 & 0.975 & 0.826 & 1.152 \\
\hline & Sabit & -0.135 & 0.261 & 0.268 & 0.604 & 0.873 & & \\
\hline
\end{tabular}

Geriye doğru değişken çıkarma yönteminde, modelden çıan değişkenlerin tekrar modele girme şansı olmadığından adımsal sonuçlar hesaplanır. Üçüncü adım sonunda senkronizasyon yöntemi, tohumlama anındaki süt verimi, vücut kondisyon skoru ve tohumlama sayısı değişkenleri modelde yer almıştır (Çizelge 3).

Çizelge 4'de her adımda modelin anlamlılığını test eden Omnibus test sonuçları verilmiştir. Her adımda elde edilen model parametrelerinin \% 95 güven aralığında anlamlı olduğu görülmüştür. Elde edilen sonuçlara göre üçüncü adımda iki modelin -2 Log Likelihood istatistikleri arasındaki fark 4 serbestlik derecesiyle 15.501 'dir. Bu değer $\chi_{(0,05 ; 4)}=9.488$ değerinden büyük olduğu için "lojistik regresyon katsayılarının hepsi aynı anda sıfıra eşittir" hipotezi reddedilir.

Her adımda, lojistik regresyon modellerindeki bağımlı değişken ile bağımsız değişkenler arasındaki ilişkinin derecesini gösteren Cox- Snell ve Nagelkerke $R^{2}$ (Pesudo $\mathrm{R}^{2}$ ) değerleri hesaplanmıştır. $\mathrm{Bu}$ değerler, üçüncü adımda bağımlı değişkenle bağımsız değişkenler arasında yaklaşık \% 12 ve \% 16'lık bir ilişki olduğunu göstermiştir. 
Çizelge 3. Geriye doğru değişken çıkarma yönteminde her adımdaki çok değişkenli lojistik regresyon modelleri

\begin{tabular}{|c|c|c|c|c|c|c|c|c|}
\hline Değişken Kodu & Değişken Sınırları & $\beta$ & $\mathrm{SE}(\beta)$ & Wald & $\mathrm{P}$ & OR & \multicolumn{2}{|c|}{$\begin{array}{c}\text { OR'nin } \% 95 \text { Güven } \\
\text { Aralığ } 1\end{array}$} \\
\hline \multicolumn{9}{|l|}{ ADIM 1} \\
\hline \multirow[t]{2}{*}{ Senkronizasyon Yöntemi } & Doğal (Referans) & 0.00 & 0.00 & & & 1.000 & 1.000 & 1.000 \\
\hline & Senkronizasyon & 0.999 & 0.477 & 4.382 & 0.036 & 2.715 & 1.066 & 6.918 \\
\hline Doğum sayısı & Sürekli değişken & 1.005 & 1.099 & 0.836 & 0.360 & 2.732 & 0.317 & 23.561 \\
\hline Süt Verimi & Sürekli değişken & -0.057 & 0.030 & 3.545 & 0.060 & 0.945 & 0.891 & 1.002 \\
\hline Vücut kondisyon skoru & Sürekli değişken & 1.319 & 0.603 & 4.790 & .029 & 3.741 & 1.148 & 12.191 \\
\hline Postpartum süre & Sürekli değişken & 0.004 & 0.004 & 0.771 & 0.380 & 1.004 & 0.995 & 1.012 \\
\hline Tohumlama sayıs1 & Sürekli değişken & -0.375 & 0.231 & 2.649 & 0.104 & 0.687 & 0.437 & 1.080 \\
\hline Model Sabiti & & -4.390 & 3.322 & 1.747 & 0.186 & 0.012 & & \\
\hline \multicolumn{9}{|l|}{ ADIM 3} \\
\hline \multirow[t]{2}{*}{ Senkronizasyon Yöntemi } & Doğal (Referans) & 0.00 & 0.00 & & & 1.000 & 1.000 & 1.000 \\
\hline & Senkronizasyon & 1.060 & 0.470 & 5.075 & 0.024 & 2.886 & 1.148 & 7.256 \\
\hline Doğum say1s1 & Sürekli değişken & 0.562 & 0.959 & 0.344 & 0.558 & 1.755 & 0.268 & 11.497 \\
\hline Süt Verimi & Sürekli değişken & -0.066 & 0.028 & 5.324 & 0.021 & 0.936 & 0.886 & 0.990 \\
\hline Vücut kondisyon skoru & Sürekli değişken & 1.346 & 0.594 & 5.127 & 0.024 & 3.841 & 1.198 & 12.314 \\
\hline Tohumlama sayıs1 & Sürekli değişken & -0.220 & .142 & 2.387 & 0.122 & 0.803 & 0.607 & 1.061 \\
\hline Model Sabiti & & -3.113 & 2.938 & 1.123 & 0.289 & 0.044 & & \\
\hline \multicolumn{9}{|l|}{ ADIM 3} \\
\hline \multirow[t]{2}{*}{ Senkronizasyon Yöntemi } & Doğal (Referans) & 0.00 & 0.00 & & & 1.000 & 1.000 & 1.000 \\
\hline & Senkronizasyon & 1.073 & 0.469 & 5.223 & 0.022 & 2.924 & 1.165 & 7.338 \\
\hline Süt Verimi & Sürekli değişken & -0.067 & 0.028 & 5.606 & 0.018 & 0.935 & 0.885 & 0.989 \\
\hline Vücut kondisyon skoru & Sürekli değişken & 1.292 & 0.585 & 4.879 & 0.027 & 3.641 & 1.157 & 11.461 \\
\hline Tohumlama sayıs1 & Sürekli değişken & -0.266 & 0.119 & 4.965 & 0.026 & 0.766 & 0.606 & 0.968 \\
\hline Model Sabiti & & -1.757 & 1.797 & 0.956 & 0.328 & 0.173 & & \\
\hline
\end{tabular}

Hosmer-Lemeshow $\hat{C}_{g}^{*}$ istatistiği sonucunda, üçüncü adımda $\chi^{2}=3.598, \mathrm{P}=0.891 \mathrm{P}>0.05$ olarak hesaplanmış, değişkenlerin modele uyumunun oldukça iyi olduğu ve lojistik regresyon modelinin ele alınan bağımsız değişkenlerle 30. günde gebelik oranını açıklamada yeterli bir model olduğu sonucuna varılmıştır (Çizelge 5).

Çizelge 4. Her adımda model katsayılarının Omnibus testleri ve modelinin Cox- Snell $\mathrm{R}^{2}$ ve Nagelkerke $\mathrm{R}^{2}$ değerleri

\begin{tabular}{|c|c|c|c|c|c|c|}
\hline & & Ki-Kare Değeri & Serbestlik derecesi & $\mathrm{P}$ değeri & Cox \& Snell $\mathrm{R}^{2}$ & Nagelkerke $\mathrm{R}^{2}$ \\
\hline \multirow[t]{3}{*}{ Adım 1} & Adım & 16.63 & 6 & 0.011 & & \\
\hline & Blok & 16.63 & 6 & 0.011 & 0.126 & 0.169 \\
\hline & Model & 16.63 & 6 & 0.011 & & \\
\hline \multirow[t]{3}{*}{ Adım 2} & Adim & -0.783 & 1 & 0.376 & & \\
\hline & Blok & 15.847 & 5 & 0.007 & 0.121 & 0.162 \\
\hline & Model & 15.847 & 5 & 0.007 & & \\
\hline \multirow[t]{3}{*}{ Adım 3} & Adım & -0.346 & 1 & 0.376 & & \\
\hline & Blok & 15.501 & 4 & 0.004 & 0.118 & 0.158 \\
\hline & Model & 15.501 & 4 & 0.004 & & \\
\hline
\end{tabular}

Geriye doğru değişken çıkarma yöntemi ile her adımda değişken katsayıları test edilmiş ve anlamsız olan değişken bir sonraki adımda modelden çıkarılmıştır. Üçüncü adımda elde edilen modelde yer alan sabit terim ve bağımsız değişken için değişken katsayılarının sıfırdan farklılı̆̆ 1 istatistik olarak önemli bulunmuştur 
Çizelge 5. Hosmer- Lemeshow $\widehat{\mathrm{C}}_{\mathrm{g}}^{*}$ istatistiği serbestlik derecesi (Sd) ve istatistik önem kontrolü (P değeri)

\begin{tabular}{cccc}
\hline Adım & Ki-Kare değeri & Sd & P Değeri \\
\hline 1 & 9.172 & 8 & 0.328 \\
2 & 1.573 & 8 & 0.991 \\
3 & 3.598 & 8 & 0.891 \\
\hline
\end{tabular}

$(\mathrm{P}<0.05)$. Yani, final modelde yer alan "senkronizasyon yöntemi, tohumlama anındaki süt verimi, vücut kondisyon skoru ve tohumlama sayısı" değişkenleri gebelik oranı üzerine etkili faktörlerdir ve oluşturan model ile gebelik olasılı̆̆ $(\mathrm{P})$;

$$
\begin{aligned}
{\left[\frac{\mathrm{P}}{1-\mathrm{P}}\right]=} & 0.173+2.924_{\text {Senkronizasyon }}+0.935_{\text {Süt }} \text { verimi }+ \\
& 3.641_{\mathrm{VKS}}+0.766_{\text {Tohumlama sayıs }}
\end{aligned}
$$

eşitliği ile tahmin edilebilir. Ayrıca bu modelin sınıflandırma başarı oranı \% 65 olarak hesaplanmıştır (Çizelge 6).

Çizelge 6. Geriye doğru değişken çıkarma yöntemi ile üçüncü adımda elde edilen modelin sınıflandırma çizelgesi

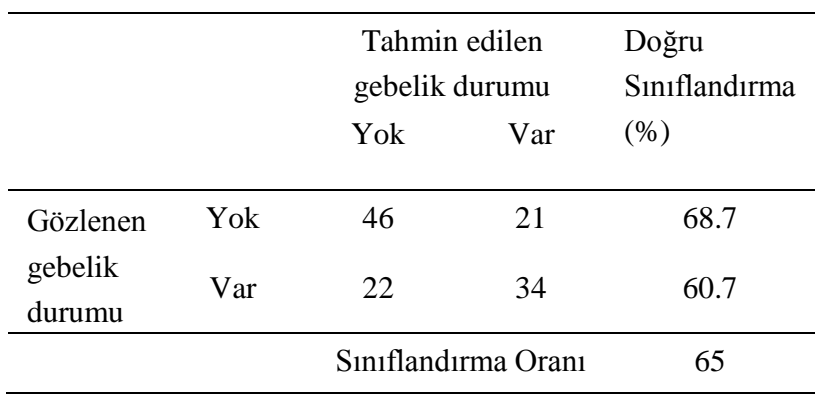

\section{Tartışma ve Sonuç}

Gebeliğin erken tanısı, optimal reprodüktif performans için önemlidir. Bu çalışmada tohumlama sonrası 30 . günde yapılan ultrasonografik muayenede tespit edilen gebelik oranı (\%45.2), daha önce yapılan çalışmalardaki gebelik oranlarılla benzer bulunmuştur (Sartori ve ark., 2002; Santos, 2004; Güzeloğlu ve ark., 2007; Erdem ve Güzeloğlu, 2010).

Oluşturulan çok değişkenli lojistik regresyon modeli incelendiğinde, progesteron preparatı ile yapılan östrus senkronizasyon yöntemi, doğal östrusa göre gebelik odds oranında \% 192 [(1- 2.924)*100] artışa; günlük süt verimindeki 1 birimlik artış gebelik odds oranında $\%$ $6.5[(1-0.935) * 100]$ azalışa; vücut kondisyon skorundaki 1 birimlik artışın gebelik odds oranında \% $264[(1-3.641) * 100]$ artışa ve tohumlama sayısındaki 1 birimlik artış gebe kalma odds oranında \% 23,4 [(10.766)*100] azalışa yol açttğı görülmüştür. Modelin hem biyolojik olarak kabul edilebilir, hem de doğru sınıflama oranının (\% 65) yeteri kadar iyi olmasından dolayı, gebelik oranı için etkili bazı faktörleri belirlemede kullanılabileceği sonucuna varılmıştır.

Araştırma sonucunda geliştirilen çok değişkenli model, bu tarz çalışmalar için sadece bir örnek teşkil etmektedir. Gelecekte, süt sığırcıllığında gebelik oranını artırmaya yönelik yapılacak çalışmalarda amaca uygun farklı bağımsız değişkenleri içeren yeni modeller geliştirilmesine katkı sağlayacaktır. Belirlenen faktörler ve bunlara ait katsayılar; daha verimli, daha sağlıklı ve daha ekonomik üretimin geliştirilmesi konusunda stratejik planlama çabaları gösteren üreticilere, gelecek dönemlerde atılacak olan yeni adımlarda ışık tutacaktır. Sonuç olarak, uygun araştırma modellerinin kurgulanması durumunda, hem analiz, hem de yorumlama kolaylığı açısından lojistik regresyon analizinin kullanımı önerilmektedir.

\section{Kaynaklar}

Bartels, C.J.M., Wouda, W., Schukken, Y.H. 1999. Risk factors for Neospora caninum-associated abortion storms in dairy herds in the Netherlands (1995 to 1997). Theriogenology 52(2): 247-257.

Bruun, J., Ersboll, A.K., Alban, L. 2002. Risk factors for metritis in Danish dairy cows. Prev. Vet. Med. 54(2): 179-190.

Cameron, R.E.B., Dyk, P.B., Herdt, T.H., Kaneene, J.B., Miller, R., Bucholtz, H.F., Liesman J.S, Vandehaar M.J., Emery, R.S. 1998. Dry cow diet, management, and energy balance as risk factors for displaced abomasum in high producing dairy herds. J. Dairy Sci. 81(1): 132-139.

Çokluk, Ö. 2010. Lojistik Regresyon Analizi: Kavram ve Uygulama. Kuram ve Uygulamada Eğitim Bilimleri 10(3):1357-1457.

Duru, S., Tuncel, E. 2004. Siyah alaca sığırlarda kuruda kalma süresi, servis periyodu ve ilkine buzağılama yaşı ile bazı süt verimi özellikleri arasındaki ilişkiler. Uludağ Üniv. Zir. Fak. Derg. 18(1): 69-79.

Erdem, H., Atasever, S., Kul, E. 2007. Gökhöyük Tarım işletmesinde yetiştirilen siyah alaca sığırların süt ve döl verim özellikleri (2. Döl Verim Özellikleri). Ondokuzmayıs Üniv. Zir. Fak. Dergisi 22(1): 47-54.

Erdem, H., Guzeloglu, A. 2010. Effect of meloxicam treatment during early pregnancy in Holstein heifers. 
Reprod. Dom. Anim. 45(4): 625-628.

Ertuğrul, O., Orman, M.N. Güneren, G. 2002. Holştayn ırkı ineklerde süt verimine ait bazı genetik parametreler. Turk. J. Vet. Anim. Sci. 26(3): 463469.

Galiç, A., Baydilli, T., Özfiliz, A., Kumlu, S. 2004. İzmir ilinde yetiştirilen siyah alaca sığırlarda sürü büyüklüğunün süt ve döl verimi özelliklerine etkisi. Hayvansal Üretim 45(2): 17-22.

Gröhn, Y.T., Rajala-Schultz, P.J. 2000. Epidemiology of reproductive performance in dairy cows. Anim. Reprod. Sci. 60-61(1): 605-614.

Güzeloğlu, A., Erdem, H., Sarıbay, M.K., Thatcher, W.W., Tekeli, T. 2007. Effect of the administration of flunixin meglumine on pregnancy rates in Holstein heifers. Vet. Rec. 160: 404-406.

Kaya, İ., Uzmay, C., Kaya, A., Akbaş, Y. 2003. Comparative analysis of milk yield and reproductive traits of Holstein-Friesian cows born in Turkey or imported from Italy and kept on farms under the Turkish-ANAFI Project. Ital. J. Anim. Sci. 2(2): 141-150.

Kaygısız, F., Elmaz, Ö. Ak, M. 2008. Süt sığırcılığında döl verimi kayıplarının işletme gelirine etkisi. Erciyes Üniv. Vet. Fak. Derg. 5(1): 5-10.

Koç, A., İlaslan, M. Karaca, O. 2004. Dalaman TİM'de yetiştirilen siyah alaca süt sığırlarının döl ve süt verimlerine ait genetik ve fenotipik parametre tahminleri: Döl verimi. Adnan Menderes Üniversitesi Ziraat Fakültesi Dergisi 1(2):43-49.

Kumuk, T., Akbaş, Y., Türkmut, L. 1999. Süt sığırcılığında döl verimine ilişkin ekonomik kayıplar ve yetiştiricilerin bilgi ve teknoloji ihtiyacı. Hayvansal Üretim 39-40(1): 1-12.

López-Gatius, F., Santolaria, P., Yaniz, J., Rutllant, J., López-Béjar, M. 2002. Factors affecting pregnancy loss from gestation day 38 to 90 in lactating dairy cows from a single herd. Theriogenology 57(4): 1251-1261.

Opsomer, G., Gröhn, Y. T., Hertl, J., Coryn, M., Deluyker, H., Kruif, A. 2000. Risk factors for post partum ovarian dysfunction in high producing dairy cows in Belgium: a field study. Theriogenology 53(4): 841-857.

Özçakır, A., Bakır, G. 2003. Tahirova tarım işletmesinde yetiştirilen siyah alaca sığırların döl ve süt verim özellikleri (1. Döl verim özellikleri). Atatürk Üniv. Ziraat Fak. Derg. 34(3): 223-228.

Özdamar, K. 2002. Paket Programlar ile İstatistiksel Veri Analizi-1. 4.bask1, Kaan Kitabevi, Eskişehir.

Pirlo, G., Miglivor, F., Speroni, M. 2000. Effect of age at first calving on production traits and on difference between milk yield returns and rearing costs in Italian Holsteins. J. Dairy Sci. 83(3): 603-608.

Pursley, J.R., Wiltbank, M.C., Stevenson, J.S., Ottobre, J.S., Garverirc, H.A., Anderson, L.L. 1997. Pregnancy rates perartificial insemination for cows and heifers inseminated at a synchronized ovulation or synchronized ovulation or synchronized estrus. J. Dairy Sci. 80(2): 295-300.

Sabo, Y.G., Sandabe, U.K., Maina, V.A., Balla, H.G. 2008. Schemes for oestrous synchronization protocols and controlled breeding programs in cattle. J. Applied Sci. 8(2): 241-251

Santos, J.E.B., Thatcher, W.W., Chebel, R.C., Cerri, R.L.A., Galvão, K.N. 2004. The effect of embryonic death rates in cattle on the efficacy of estrus synchronization programs. Anim. Reprod. Sci. 8283(1): 513-535.

Sartori, R., Sartor-Bergfelt, R., Mertens, S.A., Guenther, J.N., Parrish, J.J., Wiltbank, M.C. 2002. Fertilization and early embryonic development in heifers and lactating cows in summer and lactating and dry cows in winter. J. Dairy Sci. 85(11): 2803-2812.

Sehar, Ö., Özbeyaz, C. 2005. Orta Anadolu şartlarındaki bir işletmede Holştayn ırkı sığırlarda bazı verim özellikleri. Lalahan Hay. Araşt. Enst. Derg. 45(1): 918.

Türkyılmaz, M.K. 2005. Reproductive characteristics of Holstein cattle reared in a private dairy cattle enterprise in Aydın. Turk. J. Vet.Anim. Sci. 29(4): 1049-1052.

Uğur, F., Akkuș, S., Erdaş, Ö. 2006. Așıma açık günler sayısının siyah alaca sığırların süt verimine etkileri. Atatürk Üniv. Ziraat Fak. Derg. 37(2): 177-180.

Ulutaş, Z., Akman, N., Akbulut, Ö. 2004. Siyah-alaca ırkı sığırların 305 günlük süt verimi ve buzağılama aralığına ait genetik ve çevre varyansları tahmini. Turk. J. Vet. Anim. Sci. 28(1): 101-104

Zonturlu, A.K., İzgür, H. 2004. İneklerde değişik yollardan ve farklı dozlarda uygulanan PGF2 $\alpha$ 'nın $\left(\right.$ Dalmazin $^{\circledR}$ ) fertiliteye etkisi. Ankara Üniv. Vet. Fak. Derg. 51(1): 13-17. 